\title{
Preventive medicine
}

\section{Revisiting Rose: strategies for reducing coronary heart disease}

\author{
Douglas G Manuel, Jenny Lim, Peter Tanuseputro, Geoffrey M Anderson, David A Alter, \\ Andreas Laupacis, Cameron A Mustard
}

The way we assess risk of coronary heart disease has become more accurate in recent years. How does this affect the efficacy of primary and secondary prevention strategies?

Twenty years ago Geoffrey Rose used the examples of blood pressure and cholesterol to show that shifting the distribution curve of a single risk factor by a small amount in an entire population has a greater effect on death rates than does treating only people with high levels of that risk factor. ${ }^{12}$ Rose did not entirely discount screening and treatment, but he cautioned that it should target people at high risk of developing an adverse health outcome rather than people with a single raised risk factor such as cholesterol concentration. In the case of coronary heart disease, medical practice has evolved to include assessment of the baseline risk of disease when recommending drug treatment. Rose's argument that a population based strategy reduces more deaths from coronary heart disease than drug treatment should be re-evaluated now that the medical treatment has incorporated the high baseline risk strategy.

\section{Medical strategies for coronary heart disease}

At the time of Rose's work, the typical medical strategy was to treat people with cholesterol lowering drugs if their total cholesterol concentration was above a defined threshold (Rose used $6.2 \mathrm{mmol} / \mathrm{l}$ ). Today, we use a baseline risk strategy that recommends treatment for people with an increased risk of a coronary event or death. Risk is assessed by algorithms that include age, sex, smoking status, blood pressure, cholesterol concentration, and other behavioural or disease risk factors. ${ }^{3}{ }^{4}$ This means that cholesterol lowering drugs (typically statins) are recommended for almost everyone with pre-existing coronary heart disease because they have a high risk of an adverse event, regardless of their total cholesterol or other lipid concentrations, and statins have been shown to reduce coronary events in such people with normal lipid concentrations. New drugs such as statins have a higher (relative) benefit and fewer harmful effects than their older counterparts.

For people without coronary heart disease, treatment recommendations are more varied but again incorporate an assessment of baseline risk..$^{5-10}$ The New Zealand national guidelines most closely follow a pure baseline risk strategy by recommending statins for anyone who has a risk of $15 \%$ or greater of developing cardiovascular disease in 10 years, regardless of their lipid concentrations. ${ }^{7}$ Other guidelines typically have lipid targets that vary depending on the level of baseline risk, with lower total and low density lipopro-

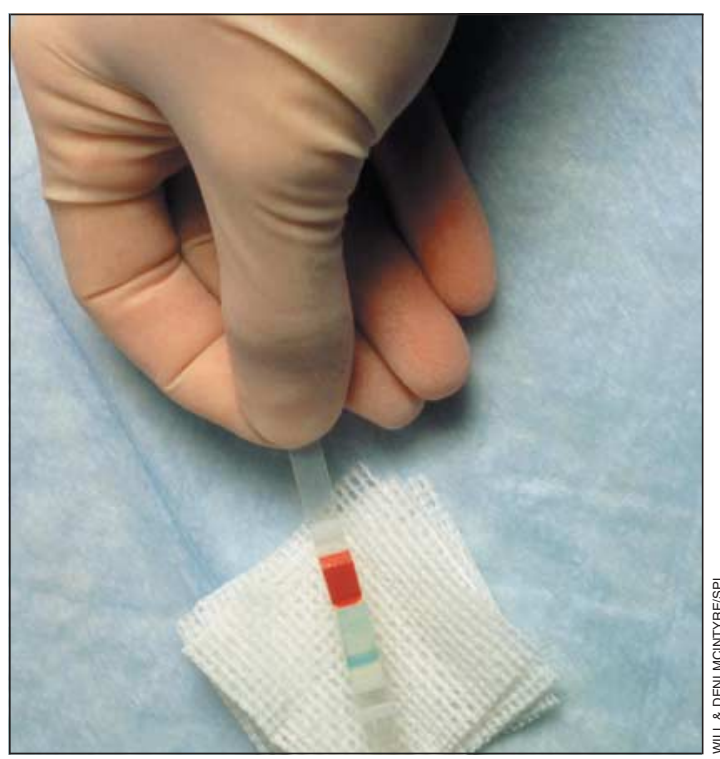

Cholesterol concentration: one of many risk factors for coronary heart disease

tein cholesterol targets for people who have higher risk.

\section{Assessing different strategies}

We set out to update Rose's work by comparing it with the baseline risk strategy used in current guidelines. We compared the number of deaths that could be avoided in Canada with three different strategies:

Population health strategy - lowering cholesterol uniformly in the entire population

Single raised risk factor strategy-treating people with a total cholesterol concentration $>6.2 \mathrm{mmol} / \mathrm{l}$ with statins (Rose's original comparison)

High baseline risk strategy-treating people with an increased risk of coronary heart disease or cardiovascular disease.

We used the recommendations of the New Zealand cardiovascular disease prevention guidelines as an example of treating people with drugs on the basis of their baseline risk of cardiovascular disease. We assessed the three different strategies to reduce coronary heart disease in the Canadian population, using the Canadian Heart Health Survey, a cross sectional, population based survey of 6760 adults that

Details of the analysis and further results are on bmj.com
Editorial by Jackson et al and Research p 629

Institute for Clinical Evaluative Sciences, G106-2075 Bayview Avenue, Toronto, ON, Canada M4N 3M5

Douglas G Manuel scientist

Jenny Lim

research coordinator Peter Tanuseputro research coordinator

David A Alter scientist

Andreas Laupacis chief executive officer

Department of

Public Health

Sciences, University

of Toronto, Toronto Geoffrey M Anderson professor

Institute for Work and Health, Toronto

Cameron A

Mustard

president and senior

scientist

Correspondence to: D G Manuel doug.manuel@ ices.on.ca

BMJ 2006;332:659-62 


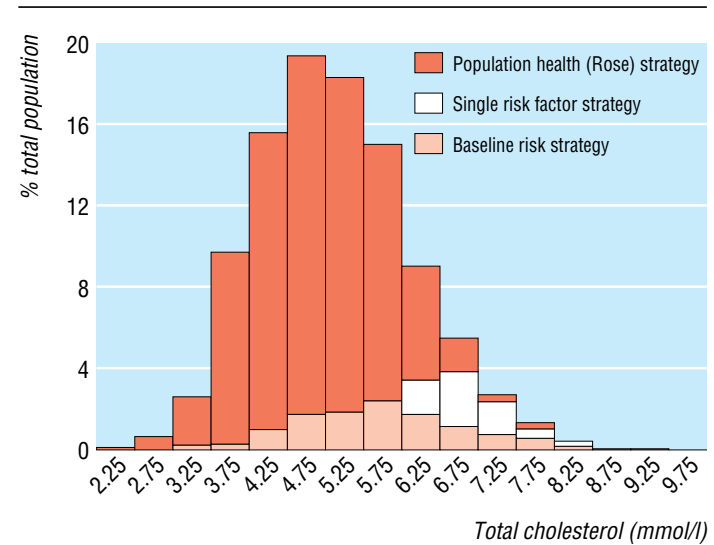

Total cholesterol concentration in populations targeted by three preventive strategies. Based on data from Canadians aged 20-74 in 1990

contained biophysical measures including blood pressure, weight, height, and blood lipid concentrations. ${ }^{11}$ The study methods are on bmj.com.

\section{Effect of different strategies}

The figure shows the distribution of total cholesterol concentration in Canadians aged 20 to 74 years in 1990 (median $5.0 \mathrm{mmol} / \mathrm{l}$ ). In all, $11.1 \%$ of the screened population had a concentration greater than $6.2 \mathrm{mmol} / \mathrm{l}$, slightly less than the $12.9 \%$ who would be treated under the high baseline risk strategy of the New Zealand guidelines (of whom $66 \%$ had a total concentration $<6.2 \mathrm{mmol} / \mathrm{l})$.

The table shows that under the population health strategy, reducing the total cholesterol concentration of each person in the population by $2 \%$ would lead to 5160 fewer deaths from coronary heart disease over 10 years (42 deaths per 100000 people). (Table A on bmj.com gives results for different risk categories). Treatment of the population under the single risk factor and high baseline risk strategies with 100\% adherence would prevent 15500 and 35800 deaths (125 and 290 deaths per 100000 ) over 10 years.

Since the effectiveness of all three strategies will vary depending on the effectiveness of the population health strategy and adherence to treatment, we also estimated the population reduction in total cholesterol against adherence to treatment for equivalent numbers of deaths avoided over 10 years. A population strategy that achieves a $2 \%$ reduction in total cholesterol concentration in the entire study population (a reduction that corresponds to the decrease observed over 10 years in the 21 country monitoring of trends and determinants in cardiovascular disease (MONICA) study ${ }^{12}{ }^{13}$ ) would reduce the same number of deaths from coronary heart disease as the New Zealand baseline risk strategy with $16 \%$ statin adherence and the single risk factor strategy with $30 \%$ adherence.

The baseline risk strategy is a more discriminating method of identifying risk of death from coronary heart disease than the high cholesterol strategy. The average death risk of people identified for treatment by the baseline risk strategy was greater at each total cholesterol interval than for the other two strategies. For example, people recommended for treatment by the New Zealand guidelines who had a total cholesterol concentration $\geq 4 \mathrm{mmol} / \mathrm{l}$ had a higher risk of death from coronary heart disease than the general population in the highest cholesterol category $(>8 \mathrm{mmol} / \mathrm{l})$. See the figure on bmj.com for a comparison of risk of coronary heart disease for different total cholesterol concentrations.

The table also shows that, when the Framingham risk assessment is used, risk of coronary heart disease is only moderately diffused in the population. Over half of the Canadian population had less than a $0.1 \%$ risk of death in 10 years from coronary heart disease (accounting for $0.5 \%$ of total deaths), while almost all $(99.9 \%)$ the people identified by using the baseline risk strategy had $1 \%$ or greater risk of death (accounting for $99.4 \%$ of total deaths).

\section{Role of high baseline risk strategy}

The modern strategy of treating people at high baseline risk, as articulated in the New Zealand guidelines, is potentially more than twice as effective at reducing death from coronary heart disease as treating people with high total cholesterol concentrations. The baseline risk strategy with reasonable adherence to statins has a potentially important role in improving coronary heart disease in the Canadian population.

The baseline risk strategy is effective because it targets a group that accounts for a large proportion of total population at risk of coronary heart disease using a treatment (statins) that has a high relative benefit. The group targeted by the New Zealand guidelines is slightly larger than that targeted by the raised total cholesterol strategy; however, the former group accounts for a much greater share of the total population risk.

\section{Which strategy should we use?}

In Canada, over half the population aged 20 to 74 years has a very low risk of death from coronary heart disease $(<0.1 \%$ risk over 10 years). Any intervention in this target population will have a small effect on population health. Information from other risk factorssuch as age, sex, blood pressure, and smoking-should be used to assess baseline risk of coronary heart

Effect of three preventive strategies on deaths from coronary heart disease over 10 years in Canadians aged 20-74

\begin{tabular}{|c|c|c|c|c|c|c|c|}
\hline \multirow[b]{2}{*}{ Strategy } & \multirow[b]{2}{*}{$\begin{array}{c}\text { No }(\%) \text { of } \\
\text { population treated }\end{array}$} & \multicolumn{4}{|c|}{$\begin{array}{l}\% \text { of treated population by } 10 \text { year risk of death } \\
(\% \text { of risk group treated })\end{array}$} & \multicolumn{2}{|c|}{ No of deaths avoided ${ }^{*}$} \\
\hline & & $<0.1 \%$ & $0.1-0.99 \%$ & $1-10 \%$ & $>10 \%$ & Over 10 years & $\begin{array}{l}\text { Per } 100000 \\
\text { population }\end{array}$ \\
\hline Population health (Rose) & $12300000(100)$ & $55.1(100.0)$ & $20.2(100.0)$ & $20.4(100.0)$ & $4.4(100.0)$ & 5160 & 42 \\
\hline High baseline risk & 1590000 (12.9) & $0.1(0.0)$ & $2.2(1.4)$ & $64.0(40.5)$ & $33.8(100.0)$ & 35800 & 290 \\
\hline Single risk factor & 1370000 (11.1) & $4.0(0.8)$ & $27.4(15.1)$ & $54.0(29.5)$ & $14.7(37.5)$ & 15500 & 125 \\
\hline
\end{tabular}

${ }^{*}$ Assuming $100 \%$ community effectiveness for the single risk factor and high baseline risk strategies and a $2 \%$ total cholesterol reduction for the Rose strategy. 
disease, regardless of whether the assessment is for population health purposes or for a treatment strategy (high baseline risk). Such an assessment of baseline risk can help estimate the potential population benefit of interventions in high or low risk groups, including interventions for single or multiple risk factors.

We have purposely avoided stating which strategy, population or baseline risk, is potentially more effective for reducing coronary heart disease. Results from a few recent studies show the challenges associated with such an assessment. Emberson and colleagues argued that a population strategy that reduces total cholesterol and hypertension by $10 \%$ is more beneficial than treating people with statins. ${ }^{14}$ However, they excluded people with existing coronary heart disease, who account for 35\% of all predicted deaths in our study. Also, a 10\% reduction in population cholesterol concentrations seems optimistic, given that existing community based interventions $^{1516}$ and large populations in industrial countries $^{12}{ }^{13}$ have not achieved this degree of reduction.

Wald and Law argued that the incidence of coronary heart disease could be reduced by $80 \%$ if all men and women over the age of 55 took a "polypill" of six low dose drugs (one of them a statin). ${ }^{17}$ The actual reduction in coronary heart disease from using this strategy is related to the population adherence to treatment. Adherence varies considerably between groups and is often difficult to assess. ${ }^{18-20}$ For this reason we have presented our findings in terms of a reduction in coronary heart disease with different levels of adherence or reductions in total cholesterol concentration.

Both population and baseline risk strategies have important roles for reducing death from coronary heart disease. A reasonable approach to reducing deaths would include both a high baseline risk strategy and a population health strategy for populations with moderate baseline risk. The extent to which one strategy should be emphasised over another depends not only on achievable effectiveness but also on cost effectiveness and other resource implications. In Canada about $1 \%$ of total healthcare expenditure, or about $\$ \mathrm{C} 1.7 \mathrm{bn}$ ( $£ 0.85 \mathrm{bn}$; $\$ 1.4 \mathrm{bn} ; € 1.2 \mathrm{bn}$ ), is spent on statins (not including visits to the doctor or laboratory costs). ${ }^{21}$ By comparison, about $2 \%$ of healthcare resources is allocated to the entire public health sector, which is responsible for population health strategies for all conditions (as well as preventive services such as immunisations). ${ }^{22}$

\section{Conclusions}

The Framingham risk algorithm shows that risk of coronary heart disease is only moderately diffused in the Canadian population. This means that medical interventions with a reasonably high relative benefit (such as statins) that are targeted in high risk populations can have an important role for improving population health outcomes. Conversely, population health strategies that target the majority of the population (people at low coronary heart disease risk) have little effect on population health outcomes because the population risk is low in this group.

Rose was critical that the medical strategy of his day focused on high levels of risk factors as opposed to

\section{Summary points}

Strategies to prevent coronary heart disease are based on the belief that risk is widely distributed

Multiple risk factors are used to estimate baseline risk in individuals

Analysis of a large national sample shows that risk is concentrated in only a modest proportion of the population

Current treatment guidelines are potentially as effective in preventing death from coronary heart disease as population-wide reductions in cholesterol

Population health strategies should evaluate baseline risk in target populations

meaningful health outcomes. Medicine has developed analytical tools, such as the Framingham risk algorithms, that use multiple risk factors to better characterise baseline risk of health outcomes. The result is a much improved effectiveness and efficiency of drug treatment for improving population coronary heart disease. Population health strategies should likewise characterise population risk using the best available methods (currently, algorithms based on multiple risk factors). This will allow population health strategies to focus efforts most economically while achieving the largest population health benefit.

Contributors and sources: DGM has a main research interest in assessing the population health benefit of health interventions. $\mathrm{He}$ is the lead researcher of the research programme, Population Health Impact Assessment Tools (PHIAT). This article arose from PHIAT working group sessions that explored ways to assess both population health and medical strategies. All authors are researchers with PHIAT. JL participated in analysis and interpretation of the data and drafting the manuscript. PT analysed and interpreted the data. DAA, AL, GMA, and CAM contributed to the study design, helped draft the manuscript, and critically revised the article. DGM is the guarantor.

Funding: Canadian Population Health Initiative.

Competing interests: None declared.

Ethical approval: Approved by Sunnybrook and Women's College Health Sciences Centre and assessed for privacy impact by the Institute for Clinical Evaluative Sciences.

1 Rose GA. The strategy of preventive medicine. Oxford: Oxford University Press, 1992.

2 Rose G. Sick individuals and sick populations. 1985. Bull World Health Organ 2001;79:990-6.

3 Liao Y, McGee DL, Cooper RS, Sutkowski MB. How generalizable are coronary risk prediction models? Comparison of Framingham and two national cohorts. Am Heart J 1999:137:837-45.

4 Anderson KM, Wilson PW, Odell PM, Kannel WB. An updated coronary risk profile. A statement for health professionals. Circulation 1991;83:35662.

5 Genest J, Frohlich J, Fodor G, McPherson R. Recommendations for the management of dyslipidemia and the prevention of cardiovascular disease: summary of the 2003 update. CMAJ 2003;169:921-4.

6 National Cholesterol Education Program. Detection, evaluation and treatment of high blood cholesterol in adults (adult treatment panel III). Bethesda, MD: US Department of Health And Human Services, National Institutes of Health, National Heart, Lung, and Blood Institute, 2002.

7 New Zealand Guidelines Group. Assessment and management of cardiovascular risk. Wellington: NZGG, 2003. www.nzgg.org.nz/ guidelines/0035/CVD_Risk_Full.pdfwww.nzgg.org.nz (accessed 29 June 2004) 8 British Heart Foundation. Updated guidelines on cardiovascular disease risk
assessment. London: BHF, 2005 . 
9 De Backer G, Ambrosioni E, Borch-Johnsen K, Brotons C, Cifkova R, Dallongeville J, et al. European guidelines on cardiovascular disease prevention in clinical practice. Third joint task force of European and other vention in clinical practice. Third joint task force of European and other
societies on cardiovascular disease prevention in clinical practice. Eur Heart J 2003;24:1601-10

10 National Heart Foundation of Australia, Cardiac Society of Australia and New Zealand. Lipid management guidelines-2001. Med J Aust 2001;175(suppl):S57-85.

11 MacLean DR, Petrasovits A, Nargundkar M, Connelly PW, MacLeod E, Edwards A, et al. Canadian heart health surveys: a profile of cardiovascular risk. Survey methods and data analysis. CMAJ 1992;146:1969-74.

12 Kuulasmaa K, Tunstall-Pedoe H, Dobson A, Fortmann S, Sans S, Tolonen $\mathrm{H}$, et al. Estimation of contribution of changes in classic risk factors to trends in coronary-event rates across the WHO MONICA project poputrends in coronary-event rates act

13 Tunstall-Pedoe H, Vanuzzo D, Hobbs M, Mahonen M, Cepaitis Z, Kuulasmaa K, et al. Estimation of contribution of changes in coronary care to improving survival, event rates, and coronary heart disease mortality across the WHO MONICA project populations. Lancet 2000;355:688700 .

14 Emberson J, Whincup P, Morris R, Walker M, Ebrahim S. Evaluating the impact of population and high-risk strategies for the primary prevention of cardiovascular disease. Eur Heart J 2004;25:484-91.
15 Shea S, Basch CE. A review of five major community-based cardiovascular disease prevention programs. II. Intervention strategies, evaluation methods, and results. Am J Health Promot 1990;4:279-87.

16 Vartiainen E, Heath G, Ford E. Assessing population-based programs to reduce blood cholesterol level and saturated fats. Int J Technol Assess Health Care 1991;7:315-26

17 Wald NJ, Law MR. A strategy to reduce cardiovascular disease by more than $80 \%$. BMJ 2003;326:1419.

18 Mantel-Teeuwisse AK, Goettsch WG, Klungel OH, de Boer A, Herings RM. Long term persistence with statin treatment in daily medical practice. Heart 2004;90:1065-6.

19 Heidenreich PA. Patient adherence: the next frontier in quality improvement. Am J Med 2004:117:130-2

20 Jackevicius CA, Mamdani M, Tu JV. Adherence with statin therapy in elderly patients with and without acute coronary syndromes. JAMA erly patients wih $2002 ; 288: 462-7$.

21 Jackevicius CA, Tu K, Filate WA, Brien SE, Tu JV. Trends in cardiovascular drug utilization and drug expenditures in Canada between 1996 and 2001. Can J Cardiol 2003;19:1359-66.

22 National Advisory Committee on SARS and Public Health. Learning from SARS. Renewal of public health in Canada. Ottawa: Health Canada, 2004

(Accepted 1 December 2005)

\title{
HIV and global health
}

\section{Global inequality of life expectancy due to AIDS}

\author{
Danny Dorling, Mary Shaw, George Davey Smith
}

Global inequality in both health and wealth began to rise worldwide in the early 1980s and has been exacerbated by AIDS in Africa. This trend is not inevitable, and historical trends show that inequality can be reduced

Department of Geography, University of Sheffield, Sheffield S10 2TN

Danny Dorling professor of human geography

Department of Social Medicine, South West Public Health Observatory,

University of

Bristol, Bristol

BS8 2PR

Mary Shaw

reader in medical

sociology

Department of

University of Bristo

George Davey

Smith

professor of clinical

epidemiology

Correspondence to:

D Dorling

Daniel.Dorling@

sheffield.ac.uk

BMJ 2006;332:662-4
Inequality in health within the United Kingdom has been widely discussed in medical, health, and social science journals, with the most recent data showing a widening of inequality between areas of the UK. ${ }^{1}$ Such inequality is also the focus of several government targets. In other wealthy countries inequality in health is both widely studied and subject to government attention. ${ }^{2}$ Recent political events such as the Make Poverty History campaign, the Live 8 concerts, the G8 summit in Scotland, the World Trade talks in Hong Kong, and the broader background of "globalisation" have turned attention towards the global picture. In this article we ask two questions: what is the state of inequality in health and wealth across the globe? and, is inequality increasing or decreasing over time?

Data from the United Nations Organisation can be used to answer the first question, ${ }^{34}$ but a suitable measure of inequality is needed to answer the second question. Moser et al suggest using a novel measure of dispersion to track trends in the distribution of global mortality over time-the dispersion measure of mortality. ${ }^{5}$ They claim that "the dispersion measure of mortality has advantages over other commonly used summary measures of mortality contrast that only use information from the extremes of the mortality or socioeconomic distribution and do not weight for size of the unit." We use another well established measure of inequality, which has the same attributes but is simpler to interpret and compute and is more informative-the slope index of inequality. ${ }^{6}$ The index can provide a simple measure of the size of the gap in natural units-in this case-years of life expectancy lost.

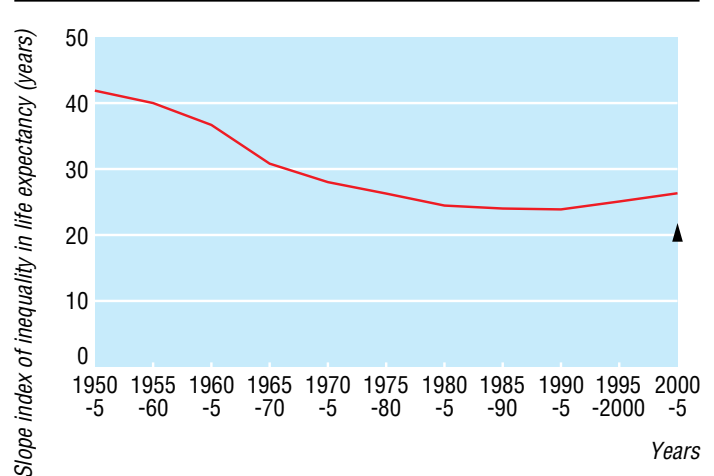

Fig 1 Global life expectancy slope index of inequality (in years). Black triangle shows estimated index in 2000-5 with impact of AIDS removed

\section{Changes over time}

Using the UN data, aggregated into six continents (see bmj.com), we calculated the slope index of inequality for life expectancy from 1950 to 2005. Data for 2001-5 form the central projection used and published by various UN statistical agencies. We calculated the index by continent rather than country for several reasons: we do not have a consistent measure of poverty or wealth to rank all countries at all points in time; data for countries in war or crisis (or both) are unreliable; the ranking of continents by gross domestic product

The nation states of the United Nations in 2002 are listed on bmi.com 